intubation after induction of general anaesthesia - both contraindicated. He later admitted he had never looked at the anaesthesia record.

At least in the United States, the medical-legal considerations may well influence what technique the anaesthetist recommends or chooses to secure the airway in the cervical injured patient requiring surgery. Although not best medically, the old method of pre-operative awake tracheostomy may be the most realistic and defensible for the anaesthetist. Should the anaesthetist be willing to assume the risk of securing the airway, some form of awake intubation followed by a thorough and documented neurological evaluation and after positioning appears to be the most judicious approach.

Anthony R. Palmer MD

907-B Medical Centre Drive

Arlington, TX 76012

\title{
REFERENCE
}

1 Tracheal intubation and cervical injury. Can $\mathbf{J}$ Anaesth 1992; 39: 1000-1.

\section{Upper airway obstruction by Ascaris worm}

To the Editor:

A 52-yr-old male patient was admitted to the Intensive Care Unit (ICU) for postoperative ventilation. He had earlier developed severe hypovolaemic shock following lumbar discectomy, for which a laparotomy had been performed to repair an aortic tear. After two hours of mechanical ventilation in ICU, the trachea was extubated and he was fully conscious and in no distress. One halfhour later, the patient suddenly developed severe stridor and became cyanosed. Urgent preparations were made to reintubate the trachea, but the patient coughed up a long object, which was found to be a $22 \mathrm{~cm}$ Ascaris worm (Figure). Immediately, the stridor disappeared and the patient's colour returned to normal.

Upper airway obstruction is a life-threatening medical emergency. Common causes are foreign bodies or inflammation, but upper airway obstruction of this nature is rarely reported.' Adult Ascaris Lumbricoides worms may migrate up to the oesophagus and enter the air passages, especially when they are irritated by certain drugs or anaesthetic agents. ${ }^{2,3}$ Acute laryngeal obstruction due to Ascaris worm, despite its rarity, should be considered, especially in areas of endemic parasitic infestation.

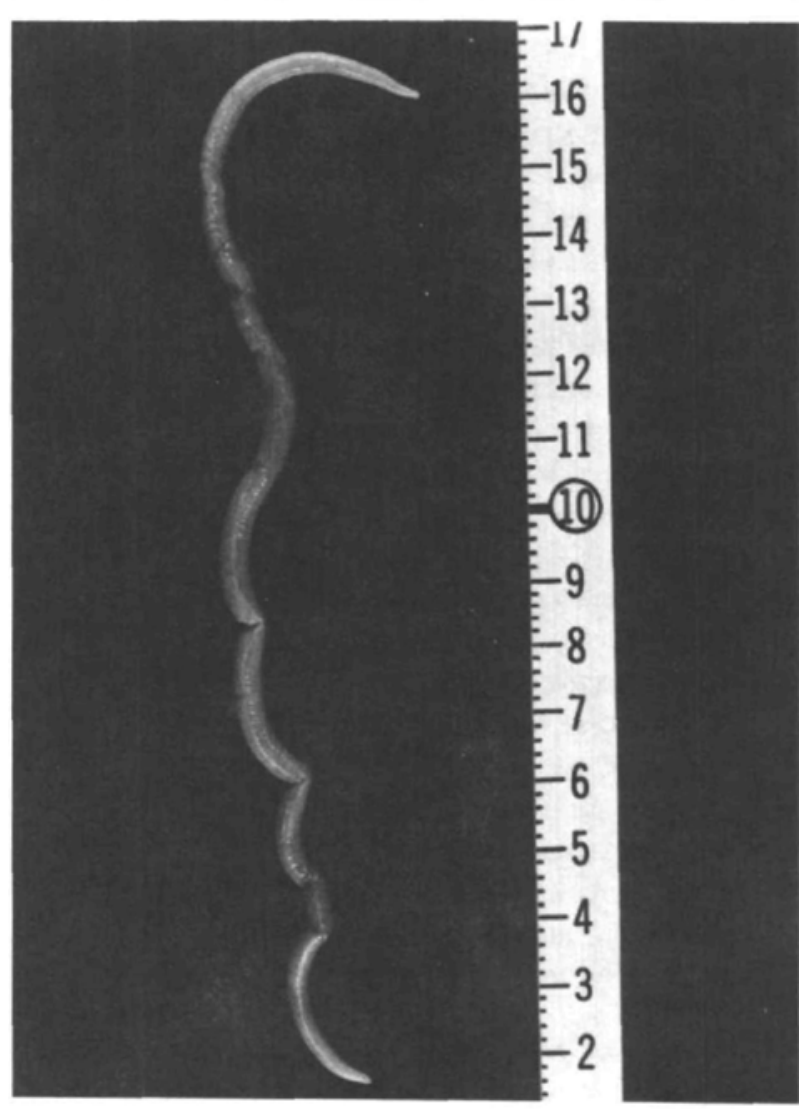

FIGURE Ascanis worm removed from the patient.

Treatment of Ascariasis before elective surgery is indicated. $^{3}$

Jafar H. Faraj MB ChB DA FFARCS

38 Harradence Close

Winnipeg, Manitoba R3Y IK5

\section{REFERENCES}

1 Solomon E. Leech - an unusual cause of (laryngotracheal) obstruction. Ethiopian Medical Journal, 1991; 29: 141.

2 Markell EK, Voge M, John DT. Medical Parasitology, 7th ed. W.B. Saunders Company, 1992, Chapter 8: 264.

3 Schroeder SA, Tierney LM, McPhee SJ, Papadakis MA, Krupp MA. Current Medical Diagnosis and Treatment. A Lang Medical Book, 1992, Chapter 29, 1133.

\section{Pre-admission clinic}

\section{To the Editor:}

We appreciate your publishing the results of the initiation of our Pre-Admission Anaesthetic Consultation Clinic.' 